\title{
Follow-Up Upper Tract Imaging Post-Nephroureterectomy for TCC: Need for a Protocol Driven Approach?
}

\author{
Srijit Banerjee, Sudhanshu Chitale ${ }^{*}$, Katherine Burnand, Neil Burgess \\ Department of Urology Norfolk \& Norwich University Hospitals NHS Foundation Trust, Norwich, UK \\ Email: "chitalenorwich@aol.com
}

Received September 11, 2012; revised December 6, 2012; accepted December 16, 2012

\begin{abstract}
Objectives: We present a retrospective analysis of follow-up strategy adapted by different clinician in managing UTUC cases. Methods: Case notes of 83 patients undergoing nephroureterectomy for UTUC at our institute were selected. Their follow-up pattern and any imaging protocols for upper tract surveillance were studied retrospectively. Results: Our study highlighted diversity in clinicians' overall approach at a time when no approved guidelines or standardised protocols were available. Conclusions: This study clearly highlighted the need for a protocol driven approach; which has lately been addressed with the introduction of EAU guidelines on this subject matter and majority of practising Urologists will adhere to it.
\end{abstract}

Keywords: Follow Up; Transitional Cell Carcinoma; Upper Tract; Urothelial

\section{Introduction}

Although uncommon, urothelial malignancy of the upper urinary tract accounts for about $5 \%$ of all urothelial tumours. [1] Current incidence is around $0.6-1 / 100,000$ person-years. Over the last few decades, radical nephroureterectomy (open/laparoscopic) has emerged as standard of care for upper tract urothelial cancer (UTUC) especially for muscle invasive and/or high-grade disease [2]. Primary tumour classification, pathologic grade, lymph node status, multifocality and tumour location have all been implicated as significant prognostic factors.

Although there has been a clear consensus on the mode of treatment for UTUC, postoperative surveillance has not been standardised until recently [3] (Table 1).

In recent years (2011) EAU has come up with up-todate guidelines for follow-up of upper tract urothelial cancer. It recommends initial cystoscopy at three months followed by yearly cystoscopy for at least five years. For contralateral upper tract it recommends MDCTU every year for five years for low-grade upper tract TCC and six monthly for two years followed by annual MDCTU for high grade upper tract TCC (Table 2). In this retrospective series, we studied the follow up pattern seen in patients who had undergone nephroureterectomy for UTUC in a single centre over a period of 10 yrs. with particular reference to the type of upper tract imaging and the interval between the imaging as well as the indications for

"Corresponding author. imaging and the findings in individual cases and their implications on further management thereby highlighting the variations and inconsistencies noted and the need for streamlining the approach for following up UTUC postnephroureterectomy.

\section{Methods}

Between 2000 and 2008, 83 patients undergoing nephroureterectomy for UTUC at our institute were selected for this study. Their follow-up pattern and any imaging protocol for upper tract surveillance were studied retrospectively. Data was collected using patient notes as well as PACS system, which is an online digitalised storage system for radiological images. Patients were identified from review of histological data, discharge summaries, clinic letters and clinical coding systems. Patients who had nephroureterectomy for benign conditions or those who had organ sparing endoscopic surgery for UTUC were excluded. The average age for the patient group was 69.9 years (range 34 - 91 years). There were 30 men and 53 women. The mean follow-up was for 41.5 months (Range: 0 - 10 years).

\section{Results}

Follow-up of the upper tract: $40(48.2 \%, \mathrm{n}=83) \mathrm{pa}-$ tients had some form of upper tract imaging throughout the follow-up period. 32 patients had CT scan and 15 patients had IVU with seven patients having both CT scan and IVU at some point during their follow-up. It 
Table 1. Follow up protocol followed by different authors in their respective studies [4-7].

\begin{tabular}{|c|c|c|c|}
\hline Author & Number of patients & Cystoscopic follow-up protocol & Upper tract follow up protocol \\
\hline Raman et al. [5] & 1249 & $\begin{array}{c}3 \text { - } 4 \text { months for } 1 \text { year } \& 6 \text { months for } 5 \\
\text { years }\end{array}$ & $\begin{array}{l}\text { CT, bone scan. MRI based on clinical } \\
\text { presentation. }\end{array}$ \\
\hline Berger et al. [6] & 145 & $\begin{array}{c}3 \text { months for } 2 \text { years, } 6 \text { months for } \\
2 \text { years, then annual }\end{array}$ & $\begin{array}{c}\text { CT and CXR every } 6 \text { monthly for } 2 \text { years and } \\
\text { annual thereafter }\end{array}$ \\
\hline $\mathrm{Ku}$ et al. [4] & 204 & $\begin{array}{c}3 \text { months (follow up interval increased } \\
\text { over time) }\end{array}$ & $\begin{array}{l}\text { CXR and IVU/CT every } 6 \text { months. In the absence } \\
\text { of recurrence, interval of follow up increased }\end{array}$ \\
\hline Novara et al. [7] & 69 & $\begin{array}{c}3 \text { - } 4 \text { months for } 2 \text { years, } 6 \text { months for } \\
3 \text { years, then annual }\end{array}$ & IVU/CT annually during follow up \\
\hline Simone et al. [1] & 80 & $\begin{array}{l}3 \text { months for } 2 \text { years } 6 \text { monthly for } \\
2 \text { years, then annual }\end{array}$ & $\begin{array}{c}\text { CXR and CT were performed } 6 \text { monthly for } 5 \\
\text { years and annually thereafter }\end{array}$ \\
\hline
\end{tabular}

Table 2. Follow up protocol as suggested by EAU guidelines 2011.

\begin{tabular}{|c|c|}
\hline After RNU, over at least 5 yr & GR \\
\hline \multicolumn{2}{|l|}{ Non-invasive tumour } \\
\hline $\begin{array}{c}\text { Cystoscopy/urinary cytology at } 3 \mathrm{mo} \text { and } \\
\text { then yearly }\end{array}$ & $\mathrm{C}$ \\
\hline MDCTU every year & $\mathrm{C}$ \\
\hline \multicolumn{2}{|l|}{ Invasive tumour } \\
\hline $\begin{array}{c}\text { Cystoscopy/urinary cytology at } 3 \mathrm{mo} \text { and } \\
\text { then yearly }\end{array}$ & $\mathrm{C}$ \\
\hline $\begin{array}{c}\text { MDCTU every } 6 \text { mo over } 2 \text { yr and then } \\
\text { yearly }\end{array}$ & $\mathrm{C}$ \\
\hline
\end{tabular}

was not obviously clear from the retrospective study whether the patients had CT urogram which would be more sensitive to identify contralateral upper tract pathology or normal portal CT to identify lymph node enlargement and metastatic disease .The timing of both CT scan and IVU was variable (3 months to 3 years) and appeared to be very much dependent on an individual patient's clinical presentation. (Figures 1 and 2). While most of the CT scans were done to rule out metastatic and recurrent disease, all IVUs where done to look at the contralateral PCS/ureter and rule out any filling defect. Whilst majority of patients had upper tract imaging at the clinician's discretion as a "routine" follow up, in two cases it was triggered by new occurrence of frank haematuria and in two further cases on account of flank pain with imaging negative for any metastasis/recurrence on the symptomatic side.

Whilst CT was sensitive in diagnosing distant metastasis and local recurrence in the operative bed/retroperitoneal nodes, it did not help diagnose asymptomatic contralateral recurrent disease at an early stage.

Of the 15 patients who had IVU, 13 came back normal and 2 suggested filling defects however, on ureteroscopic examination only 1 had confirmed recurrence of TCC on the contralateral ureter. 3 patients were found to have contralateral ureteric tumour recurrence and 14 patients had evidence of metastatic disease on CT scan. Overall

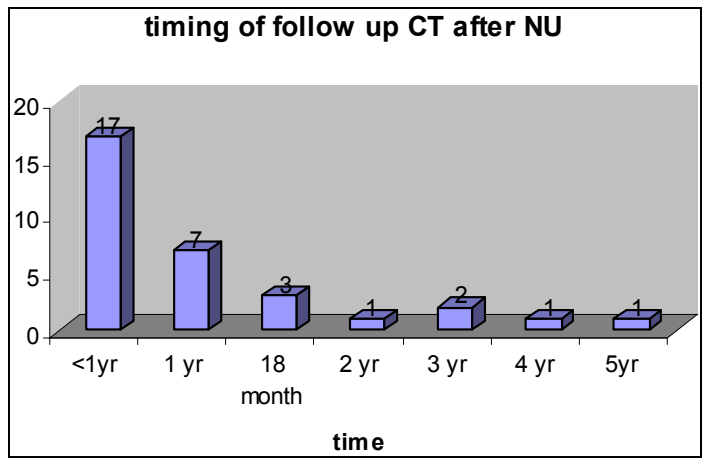

Figure 1. Follow up CT after nephroureterectomy.

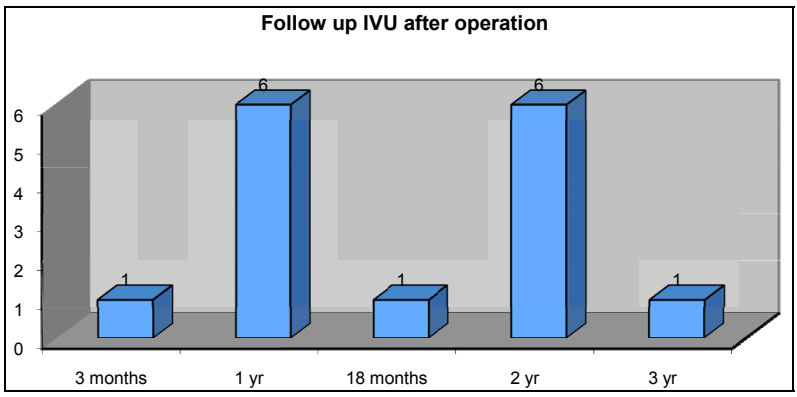

Figure 2. Follow up IVU after nephroureterectomy.

recurrence rate in our study in the contralateral ureter was $4.8 \%$ ( 4 out of 83 patients). If the recurrence rate was calculated based only on patients having had contralateral upper tract imaging the recurrence rate would be higher at $10 \%$ (4 out of 40 ). We believe that the overall recurrence rate could have possibly been higher had all patients undergoing nephroureterectomy for UTUC had regular upper tract imaging over a long term.

Cystoscopic follow-up of lower urinary tract: A wide variation was noted with the cystoscopic follow-up after nephroureterectomy (Figure 3). 39 patients (46.9\%) had their first cystoscopy at three months post operative whereas five patients $(6 \%)$ had their first cystoscopy after one year. 15 patients $(18 \%)$ did not have any cystoscopic follow-up at all.

32 patients $(38.5 \%)$ had a recurrent bladder tumour at 


\section{CYSTOSCOPY}

\begin{tabular}{|l|l|}
\hline $\begin{array}{l}1^{\text {st }} \text { POST OP } \\
\text { CYSTOSCOPY }\end{array}$ & Number of patients \\
\hline 3 months & 39 \\
\hline 6 months & 22 \\
\hline 9 months & 2 \\
\hline 12 months & 5 \\
\hline None & 15 \\
\hline TCC recurrence $18 / 68=(26.5 \%)$ \\
\hline SCC occurrence $1 / 68=(1.5 \%)$ \\
\hline No recurrence $49 / 68=(72.1 \%)$ \\
\hline \multicolumn{2}{|l}{ CYSTOSCOPY } \\
\hline $\begin{array}{l}\text { nd POST OP } \\
\text { CYSTOSCOPY }\end{array}$ & Number of patients \\
\hline 3 months & 23 \\
\hline 6 months & 34 \\
\hline 9 months & 1 \\
\hline 12 months & 3 \\
\hline None & 7 \\
\hline TCC recurrence $16 / 61=(26.2 \%)$ \\
\hline CIS occurrence $1 / 61=(1.6 \%)$ \\
\hline No recurrence 43/61 = (70.5\%) \\
\hline
\end{tabular}

Figure 3. Distribution of patients undergoing cystoscopic surveillance and incidence of recurrent bladder tumours.

some stage during their follow-up. Of these 32 , seven $(21.9 \%)$ had previous history of bladder tumour before UTUC was detected. $25 / 32$ patients (78.1\%) had a new bladder recurrence following nephroureterectomy.

\section{Discussion}

Our study clearly demonstrates that there has been a wide variation between clinicians when it comes to organising follow-up of patients post nephroureterectomy for UTUC. The recurrence rate in the contralateral ureter in the present series was $4.8 \%$. Such a low incidence of contralateral upper tract recurrence questions the rationale behind subjecting all patients to upper tract imaging and followup and should therefore be tailored to individual patients based on their clinical presentation.

The recurrence in the bladder was much higher (38.6\%) and as such patients should have a much more structured follow-up of their lower urinary tract. Less than half the patients $(46.9 \%)$ had their first cystoscopy at three months. For effective upper tract surveillance, a combination of IVU/CT at intervals agreed upon locally and backed up by flexible ureteroscopic assessment in selected cases has been advisable in view of the poor sensitivity of the radiological imaging modalities. As no standardised follow-up protocol was available until recently it appears that clinicians followed their own protocol on a case-to- case basis. With the introduction of EAU guidelines, we believe this issue has been appropriately addressed and would expect clinicians to adhere to such a standardised protocol for follow up of their patients with UTUC.

\section{REFERENCES}

[1] G. Simone, R. Papalia, S. Guaglianone, M. Ferriero, C. Leonardo, E. Forastiere and M. Gallucci, "Laparoscopic versus Open Nephroureterectomy: Perioperative and Oncology Outcomes from a Randomised Prospective Study," European Urology, Vol. 56, No. 3, 2009, pp. 520526. doi:10.1016/j.eururo.2009.06.013

[2] U. Capitanio, S. F. Shariat, H. Isbarn, A. Weizer, M. Remzi, M. Roscigno, E. Kikuchi, J. D. Raman, et al., "Comparison of Oncologic Outcomes for Open and Laparoscopic Nephroureterectomy: A Multi-Institutional Analysis of 1249 Cases," European Urology, Vol. 56, No. 1, 2009, pp. 1-9. doi:10.1016/j.eururo.2009.03.072

[3] S. E. Canfield, C. P. N. Dinney and M. J. Droller, "Surveillance and Management of Recurrence for Upper Tract Transitional Cell Carcinoma," Urology Clinics of North America, Vol. 30, No. 4, 2003, pp. 791-802.

[4] J. H. Ku, W. S. Choi, C. Kwak and H. H. Kim, "Bladder Cancer after Nephroureterectomy in Patients with Urothelial Carcinoma of the Upper Urinary Tract," Urological Oncology, Vol. 29, No. 4, 2011, pp. 383-387.

[5] J. D. Raman, C. K. Ng, D. S. Scherr, V. Margulis, Y. Lotan, K. Bensalah, J. J. Patard, E. Kikuchi, F. Montorsi, R. Zigeuner, A. Weizer, C. Bolenz, T. M. Koppie, H. Isbarn, C. Jeldres, W. Kabbani, M. Remzi, M. Waldert, C. G. Wood, M. Roscigno, M. Oya, C. Langner, J. S. Wolf, P. Ströbel, M. Fernández, P. Karakiewcz and S. F. Shariat, "Impact of Tumor Location on Prognosis for Patients with Upper Tract Urothelial Carcinoma Managed by Radical Nephroureterectomy," European Urology, Vol. 57, No. 6, 2010, pp. 1072-1079. doi:10.1016/j.eururo.2009.07.002

[6] A. Berger, G. P. Haber, K. Kamoi, M. Aron, M. M. Desai, J. H. Kaouk and I. S. Gill, "Laparoscopic Radical Nephroureterectomy for Upper Tract Transitional Cell Carcinoma: Oncological Outcomes at 7 Years," Journal of Urology, Vol. 180, No. 3, 2008, pp. 849-854. doi:10.1016/i.juro.2008.05.042

[7] G. Novara, V. De Marco, O. Dalpiaz, A. Galfano, V. Bouygues, M. Gardiman, G. Martignoni, J. J. Patard, W. Artibani and V. Ficarra, "Independent Predictors of Contralateral Metachronous Upper Urinary Tract Transitional Cell Carcinoma after Nephroureterectomy: Multi-Institutional Dataset from Three European Centers," International Journal of Urology, Vol. 16, No. 2, 2009, pp. 187191. doi:10.1111/i.1442-2042.2008.02201.x 